\title{
Prevalence and antimicrobial susceptibility of Listeria spp. isolated from bulk raw milk in north-eastern Poland
}

\author{
(1) MARTA SOŁTYSIUK, (DAGNIESZKA WISZNIEWSKA-ŁASZCZYCH, \\ (1) JOANNA WOJTACKA, (DBEATA WYSOK
}

\begin{abstract}
Department of Veterinary Public Health, Faculty of Veterinary Medicine, University of Warmia and Mazury in Olsztyn, Oczapowskiego 14, 10-957 Olsztyn, Poland
\end{abstract}

Sołtysiuk M., Wiszniewska-Łaszczych A., Wojtacka J., Wysok B.

Prevalence and antimicrobial susceptibility of Listeria spp. isolated from bulk raw milk in north-eastern Poland

Summary

The aim of the study was to determine the presence of Listeria spp. strains in the milk samples obtained from dairy farms in north-eastern Poland and to determine the profile of resistance to antibiotics recommended in the treatment of listeriosis.

500 samples of bulk milk were analyzed. Milk samples were obtained from dairy farms located in Warmia and Mazury region in Poland. Chronic mastitis, requiring frequent and long-term use of antibiotics has been documented in these herds. Isolation of Listeria spp. was performed according to the standard procedure PN-EN ISO 11290-1: 2017-07. Antibiotic resistance testing was performed by the disc diffusion method according to the Clinical \& Laboratory Standards Institute (CLSI) recommendations.

In total, out of 500 samples of pooled milk, based on biochemical properties, 8 isolates were confirmed as belonging to the genus Listeria (1.6\%). The further identification of Listeria strains on the basis of MicrobactListeria12L showed that 3 strains $(3 / 8,37.5 \%)$ belonged to $L$. monocytogenes species and 5 strains $(5 / 8,62.5 \%)$ belonged to $L$. innocua species. The analysis of sensitivity to commonly used antimicrobial agents showed that all isolates, both belonging to $L$. monocytogenes and $L$. innocua species, were sensitive to ampicillin. Multidrug resistance, defined as resistance to at least three classes of antibiotics, was confirmed among four isolates $(\mathbf{5 0 \%})$.

The studies undertaken revealed that raw milk can pose a risk for public health due to the prevalence of pathogenic Listeria spp. among which multidrug resistant strains are present. It is therefore necessary to rationalize the use of antibiotics and to monitor bacterial resistance in the food production environment.

Keywords: Listeria spp., contamination, antibiotic resistance, raw milk

Listeria spp. are widely distributed in the environment and are detected in samples of soil, plants, silage, manure, sewage or water (13). The environment of the digestive tract constitutes an ideal condition for the existence of this pathogen, therefore Listeria spp. is isolated from the intestine content of mammals, birds, fish, reptiles, amphibians, crustaceans and insects $(34,37)$. The presence of Listeria spp. both in animal and plant materials and in food is the consequence of its widespread occurrence in the environment, high resistance to physical and chemical factors, as well as the ability to survive and multiply in a wide range of temperatures. Dairy products made of unpasteurized milk, ripened raw sausages, smoked fish and industrially produced Ready-To-Eat (RTE) are most commonly contaminated foods $(23,42,50)$.

Bacteria of the genus Listeria, especially L. monocytogenes, are responsible for occasional but serious infections, both in humans and animals, causing a disease called listeriosis. In humans, two species are responsible for causing infection: L. monocytogenes and, less frequently, L. ivanovii. The elderly, pregnant women and newborns, allergy sufferers, diabetics, people with reduced immunity and after transplantation, i.e. people from the high-risk group of the so-called YOPI (Young, Old, Pregnant, Immunocompromised) are the 
most susceptible to a severe course of disease $(31,53$, 54). There are few reports on cases of listeriosis in humans caused by L. ivanovii $(17,46)$. Listeriosis can take the form of both sporadic disease and epidemic outbreaks with high mortality. In 2019, overall case mortality of listeriosis in the EU was high (17.6\%) and increased compared to the levels noticed in 2018 $(13.6 \%)$ and 2017 (15.6\%). The number of reported deaths from listeriosis in relation to the rates of campylobacteriosis $(0.03 \%)$ and salmonellosis $(0.22 \%)$ is significantly higher, which makes listeriosis one of the most serious foodborne diseases. In 2019, 28 Member States reported 2,621 confirmed invasive cases of listeriosis in humans with an EU reporting rate of 0.46 per 100,000 inhabitants. According to a report of the European Food Safety Authority (EFSA), published in 2021, listeriosis ranks fifth among the most frequently reported zoonoses in Europe $(10,11)$.

Antibiotic therapy is one of the most effective forms of treatment of prolongated or severe bacterial infections occurring in humans and animals. However, the growing number of pathogens resistant to antimicrobial agents has a significant impact on their effectiveness. Currently, antibiotic therapy is the only treatment for listeriosis. The antibiotics of first choice are usually penicillin, ampicillin and amoxicillin. In patients sensitive to penicillin, treatment with trimethoprim/ sulfamethoxazole (TMP/SMX) is alternatively used in listeriosis. Erythromycin (recommended for pregnant women), meropenem, linezolid, rifampin and vancomycin are other antibiotics recommended in the treatment of listeriosis $(22,30,48)$.

The aim of the study was to determine the presence of Listeria strains in milk samples obtained from dairy farms in north-eastern Poland and to determine the profile of resistance to antibiotics recommended in treatment of listeriosis.

\section{Material and methods}

Isolation and identification. Milk samples were obtained from dairy farms located in Warmia and Mazury region in Poland. Chronic mastitis, requiring frequent and long-term use of antibiotics has been documented in these herds.

The 500 samples of bulk milk were stored at $4{ }^{\circ} \mathrm{C}$ and analyzed within 6 hours after their collection. Isolation of Listeria spp. was performed according to the standard procedure (39). Briefly, $25 \mathrm{ml}$ of each sample was introduced into $225 \mathrm{ml}$ of broth medium half-Frazer (BioMaxima), and incubated aerobically at $30^{\circ} \mathrm{C}$ for $24 \mathrm{~h} \pm 2 \mathrm{~h}$. Next $0.1 \mathrm{ml}$ of the culture was transferred to $10 \mathrm{ml}$ of Frazer medium (BioMaxima) and subjected to further incubation at $37^{\circ} \mathrm{C}$ for $24 \mathrm{~h} \pm 2 \mathrm{~h}$. From the obtained culture two parallel isolations were performed onto agar Ottaviani $i$ Agosti ALOA (BioMaxima) and Palcam agar (BioMaxima). After 24-48 hours of incubation at $37^{\circ} \mathrm{C}$, the colonies were assessed for phenotypic features characteristic of Listeria spp. In order to determine the species affiliation of the isolated microorganisms, five colonies with morphological features typical of Listeria spp. were selected from all the inoculated plates and were then plated on TSEYA agar (BioMaxima) and incubated for $18 \mathrm{~h} \pm 2 \mathrm{~h}$. Next Gram-stained microscope slides were prepared to determine the morphology of bacterial cells, and a biochemical series of MicrobactListeria12L (Oxoid-Argenta) were performed to determine the ability to hydrolyse esculin, to hemolyse and the utilization of 11 carbohydrates. The test was performed in accordance with the manufacturer's instructions. Based on the results of the analysis of biochemical series, the species of isolated strains were determined.

Antimicrobial susceptibility testing. Antibiotic resistance testing was performed by the disc diffusion method according to the Clinical \& Laboratory Standards Institute (CLSI) recommendations. Each selected colony was suspended in physiological saline to obtain a density of $0.5 \mathrm{McF}$ arland. The suspension obtained was spread on the surface of Mueller-Hinton agar medium (BioMaxima) with the addition of $5 \%$ defibrinated horse blood (BioMaxima) and $20 \mathrm{mg} / \mathrm{L} \beta-\mathrm{NAD}$ (MH-F) (Oxoid), and then discs soaked with an antibiotic in given concentrations: erythromycin $(15 \mu \mathrm{g})$, ampicillin $(2 \mu \mathrm{g})$, meropenem $(10 \mu \mathrm{g})$, trimethoprim-sulfamethoxazole $(1.25-23.75 \mu \mathrm{g})$ were placed there. The plates were incubated at $37^{\circ} \mathrm{C}$ for $18 \pm 2 \mathrm{~h}$ in aerobic atmosphere. Inhibition zones were designated according to the CLSI standards.

\section{Results and discussion}

Health condition of dairy cows, hygienic conditions of the farm and milking are the most important factors determining the microbiological quality of milk. In most cases, milk within the mammary gland does not contain pathogenic bacteria, although microorganisms such as Brucella spp. (15), Clostridium spp. (24), Salmonella spp. (8, 57), Staphylococcus aureus (8, $25,34)$, Bacillus cereus (40), Escherichia coli $(8,36)$, Listeria monocytogenes $(8,16,38)$ and Campylobacter spp. $(5,20,58)$ were isolated from milk samples in different geographical regions. In recent years, increasing attention has been paid to listeriosis outbreaks related to the consumption of food contaminated by L. monocytogenes. This fact constitutes a significant risk of foodborne infections in humans due to consumption of dairy products. Milk and its products, due to the high content of nutrients, are popular among consumers, simultaneously in these products the development and multiplication of Listeria strains occur. According to data published by EFSA (10), unpasteurized milk and dairy products contaminated with Listeria spp. are the most common causes of listeriosis in humans. In the present study, out of 500 samples of pooled milk, 12 were positive for strains exhibiting the characteristic features of phenotypes for the genus Listeria-bluegreen colonies surrounded or not by a cloudy zone around the colony. Identification of Listeria strains on the basis of MicrobactListeria12L reagent showed that 3 strains $(3 / 8,37.5 \%)$ belonged to L. monocytogenes species and 5 strains $(5 / 8,62.5 \%)$ belonged to L. innосиа species. The overall prevalence rate of Listeria spp. was estimated at the level of $1.6 \%$. There are nu- 
Tab. 1. Antimicrobial susceptibility of Listeria spp. strains isolated from bulk raw milk

\begin{tabular}{|c|c|c|c|c|c|c|c|c|c|c|c|c|c|}
\hline \multirow[b]{2}{*}{ Strain } & \multirow[b]{2}{*}{ Number } & \multicolumn{3}{|c|}{ Erythromycin (E) } & \multicolumn{3}{|c|}{ Meropenem (MEM) } & \multicolumn{3}{|c|}{$\begin{array}{l}\text { Trimethoprim- } \\
\text { sulfametaxazole (SXT) }\end{array}$} & \multicolumn{3}{|c|}{ Ampicillin (AMP) } \\
\hline & & $\begin{array}{c}\text { Reference } \\
\text { Values - } \\
\text { EUCAST }\end{array}$ & $\begin{array}{c}\text { Test zone } \\
\text { value } \\
\text { (mm) }\end{array}$ & $\mathrm{R} / \mathrm{S}$ & $\begin{array}{c}\text { Reference } \\
\text { Values - } \\
\text { EUCAST }\end{array}$ & $\begin{array}{l}\text { Test zone } \\
\text { value } \\
\text { (mm) }\end{array}$ & $R / S$ & $\begin{array}{c}\text { Reference } \\
\text { Values - } \\
\text { EUCAST }\end{array}$ & $\begin{array}{l}\text { Test zone } \\
\text { value } \\
\text { (mm) }\end{array}$ & $R / S$ & $\begin{array}{l}\text { Reference } \\
\text { Values - } \\
\text { EUCAST }\end{array}$ & $\begin{array}{l}\text { Test zone } \\
\text { value } \\
\text { (mm) }\end{array}$ & $R / S$ \\
\hline \multirow{3}{*}{ L. monocytogenes } & 1 & \multirow{8}{*}{$\begin{array}{l}S \geq 25 \\
R<25\end{array}$} & 24 & $\mathbf{R}$ & \multirow{8}{*}{$\begin{array}{l}S \geq 26 \\
R<26\end{array}$} & 30 & $S$ & \multirow{8}{*}{$\begin{array}{l}S \geq 29 \\
R<29\end{array}$} & 33 & $S$ & \multirow{8}{*}{$\begin{array}{l}S \geq 16 \\
R<16\end{array}$} & 22 & S \\
\hline & $3^{a}$ & & 23 & $\mathbf{R}$ & & 25 & $\mathbf{R}$ & & 23 & $\mathbf{R}$ & & 17 & $\mathbf{S}$ \\
\hline & $5^{a}$ & & 18 & $\mathbf{R}$ & & 24 & $\mathbf{R}$ & & 19 & $\mathbf{R}$ & & 19 & S \\
\hline \multirow{5}{*}{ L. innocua } & 2 & & 24 & $\mathbf{R}$ & & 28 & S & & 27 & $\mathbf{R}$ & & 22 & $S$ \\
\hline & 4 & & 25 & $S$ & & 27 & S & & 17 & $\mathbf{R}$ & & 22 & $\mathbf{S}$ \\
\hline & $6^{a}$ & & 23 & $\mathbf{R}$ & & 22 & $\mathbf{R}$ & & 24 & $\mathbf{R}$ & & 19 & $S$ \\
\hline & $7^{\mathrm{a}}$ & & 21 & $\mathbf{R}$ & & 23 & $\mathbf{R}$ & & 21 & $\mathbf{R}$ & & 19 & S \\
\hline & 8 & & 24 & $\mathbf{R}$ & & 32 & $S$ & & 26 & $\mathbf{R}$ & & 21 & $S$ \\
\hline
\end{tabular}

Explanations: $\mathrm{R}$ - resistant; $\mathrm{S}$ - susceptible; a - multidrug resistance strain (MDR)

merous data on the contamination of milk and cheese by Listeria spp. (41), however the contamination levels vary significantly between different geographical regions ranging from $1.46 \%$ in Cyprus (6) to $23 \%$ in Mexico (51). Interestingly, in Syria, the prevalence of Listeria spp. was recorded in $16.2 \%$ of raw cow's milk samples and in $12.4 \%$ of sheep's milk samples and in none of the goat's milk samples (2). Taking into consideration the species identification, the findings of our study showed the prevalence of $L$. monocytogenes in $0.6 \%$ of bulk tank milk samples. Similar results, was recorded previously in Sweden at the level of $1.0 \%$ (52) and in Latvia at the level of 1.4\% (26). In turn, a higher prevalence rates of $L$. monocytogenes were found in Iran (5\%) (32), Morocco (5.9\%) (12) and the U.S. (6.5\%) (49). Simultaneously in our studies the majority of positive samples $(5 / 8,62.5 \%)$ we identified as L. innocua with the overall prevalence rate at the level of $1.0 \%$. These findings are in accordance with the results obtained by Jamali et al. (21) who reported the prevalence rate of $L$. innocua at the level of $57.8 \%$. The remaining isolates identified by these authors were as follows: L. monocytogenes $-21.7 \%$, L. welshimeri $-12 \%$ and $L$. seeligeri $-8.4 \%$. In contrast Al-mariri et al. (2) noticed L. monocytogenes as the most prevalent isolate $(41.6 \%)$, while the remaining isolates were L. innocua $(17.8 \%)$, L. ivanovii (14.2\%), L. welshimeri $(9.5 \%)$ and L. grayi (4.7\%). Moreover Listeria spp. is also often isolated from different kinds of cheese. Rahimi et al. (41) found that $28.3 \%$ of cheese that had been made from raw milk were contaminated with Listeria spp., while Rudolf and Scherer (43) noted a high prevalence rate $(8.0 \%)$ of $L$. monocytogenes in soft and semi-soft cheeses produced from pasteurized milk.

In recent years, special attention is paid to the constantly growing antibiotic resistance of microorganisms present in food, which is a significant problem in the protection of public health. Resistance to antibiotics is also noted among Listeria strains isolated from food, including milk and milk products $(3,45)$, which is especially hazardous to humans because antibiotic therapy is necessary in more serious cases of listeriosis. The majority of Listeria strains are sensitive to amikacin, ciprofloxacin, chloramphenicol, clindamycin, doxycycline, rifampin, vancomycin, and co-trimoxazole $(9,22,48)$. Ampicillin alone or in combination with gentamicin are the most common antibiotics used for the treatment of Listeria infection. However, in patients with allergies or conditions excluding penicillin therapy, second-line drugs including trimethoprim/sulfamethoxazole, erythromycin, vancomycin and fluoroquinolones are recommended $(9,48)$. In the treatment of pregnant women, erythromycin is a particularly recommended antibiotic. Despite recommendations given there is a real problem in the increasing frequency of resistance of Listeria spp. to antimicrobial agents commonly used in treatment of listeriosis, including a significant percentage of multidrug-resistant strains $(9,22,48)$.

In this study all isolated strains of $L$. monocytogenes and $L$. innocua were sensitive to ampicillin (Tab. 1). These findings are in accordance with the previous studies conducted by Korsak and Szuplewska (28), Korsak et al. (27) and Babacan (4) showing that $100 \%$ of L. monocytogenes, L. innocua, L. welshimeri, L. seeligeri and $L$. grayi strains obtained from food and food processing environments and L. monocytogenes, L. innocua and L. ivanovii isolated from cow's milk were sensitive to ampicillin. However some authors noticed the resistance of Listeria spp. to $\beta$-lactams. In the studies conducted by Skowron et al. (45) penicillin resistance was the most common in Listeria isolates originating from milk (44.4\%). An extremely high resistance rate of $L$. monocytogenes strains isolated from dairy farms to ampicillin, at the level of $92 \%$, was noted by Srinivasan et al. (47).

Treatment of listeriosis is commonly undertaken with a combination of ampicillin and gentamicin, but meropenem in monotherapy has been found active 
$(19,29)$. Meropenem is a broad-spectrum $\beta$-lactam from the carbapenem group. The results of studies published by Carryn et al. (7) and Marco et al. (33) showed a significantly low minimal inhibitory concentration against $L$. monocytogenes. Similarly, in vitro studies stressed the high susceptibility of Listeria spp. to this antibiotic. The studies performed by Babacan (4) showed that all Listeria strains originating from cow milk were sensitive to meropenem. In our study, sensitivity to meropenem was found among 4 out of 8 Listeria strains (50\%), as well as in one L. monocytogenes strain and in three L. innocua strains. Similar results were presented by Skowron et al. (44), who showed high resistance of isolated $L$. monocytogenes strains to meropenem at the level of $33.3 \%$. Also Aksoy et al. (1) noticed $6.7 \%$ of L. monocytogenes strains resistant to meropenem. Moreover, in the present study high resistance was noticed in relation to erythromycin (100\% of L. monocytogenes and $80 \%$ of L. innocua) and trimethoprim/sulfamethoxazole (66.6\% of L. monocytogenes and $100 \%$ of L. innocua). Aksoy et al. (1) and Skowron et al. (44) noted 26.7\% and $66.6 \%$ of trimethoprim/sulfamethoxazole resistant Listeria strains, respectively $(1,44)$. These findings suggest that systematic susceptibility testing should be performed before prescribing trimethoprim as a therapeutic alternative in case of first-line treatment failure or intolerance to $\beta$-lactams (35). Moreover in our studies an extremely high resistance was observed against erythromycin (7/8, 87.5\%). Also Morvan et al. (35) observed the high rate of resistance to erythromycin among L. monocytogenes isolates obtained from clinical samples (35). According to Morvan et al. (35) resistance in this case could be due to a chromosomal mutation. In turn Skowron et al. (45) noticed only a single $L$. monocytogenes strain isolated from soft cheese resistant to this antimicrobial agent. Whereas Babacan (4) noticed that all L. monocytogenes, L. innocua and L. ivanovii isolates originating from cow's milk were sensitive to erythromycin and sulfamethoxazole/trimethoprim.

Relatively high resistance to meropenem, erythromycin and trimethoprim/sulfamethoxazole observed in our study may be a result of long-term antibiotic therapy of herds of dairy cows. In our study, $50 \%$ of all tested isolates ( 2 strains of L. monocytogenes and 2 strains of $L$. innocua) were described as multidrugresistant with a E_MEM_SXT resistance pattern (Tab. 1). However, the level of drug resistance was higher in L. monocytogenes strains $(66.7 \%)$ than in L. innocua $(40 \%)$. A similar level of antibiotic resistance was presented by Aras and $\operatorname{Ard}_{1}$ (3), where $66.7 \%$ of $L$. monocytogenes and $62.5 \%$ of $L$. innocua strains were resistant to at least three of antimicrobial agent tested. The increasing resistance to several groups of antibiotics has been significantly worrisome for the recent years.
The studies undertaken revealed that raw milk can pose a risk for public health due to the prevalence of pathogenic Listeria strains among which multidrug resistant strains are present. Moreover isolated strains showed high sensitivity only to one group of tested antibiotics, while the remaining antimicrobial agents showed limited use due to significant resistance rate.

The results obtained show a significant weakness in the treatment of both animals and humans. It is therefore necessary to rationalize the use of antibiotics and to monitor bacterial resistance in the food production environment. Due to the small number of strains against which AST (antimicrobial susceptibility testing) was applied, it is justified to continue research in the field of antibiotic resistance, especially among strains obtained from dairy cattle herds.

\section{References}

1. Aksoy A., Sezer Ç., Vatansever L., Gülbaz G.: Presence and antibiotic resistance of Listeria monocytogenes in raw milk and dairy products. Kafkas. Univ. Vet. Fak. Derg. 2018, 24 (3), 415-421

2. Al-mariri A., Abou Younes A., Ramadan L.: Prevalence of Listeria spp. in raw milk in Syria. Bulg. J. Vet. Med. 2013, 16 (2), 112-122.

3. Aras Z., Ardl M.: Occurrence and antibiotic susceptibility of Listeria species in Turkey meats. Korean J. Food Sci. An. 2015, 35 (5), 669-673.

4. Babacan O.: Determination of the presence and antibiotic resistance of Listeria species and aerobic mesophilic bacteria count of cow milks. J. Turk. Med Vet. Sci. 2021, 92 (1), 16-23.

5. Bianchini V., Borella L., Benedetti V., Parisi A., Miccolupo A., Santoro E., Recordati K., Luini C. M.: Prevalence in bulk tank milk and epidemiology of Campylobacter jejuni in dairy herds in Northern Italy. Appl. Environ. Microb. 2014, 80 (6), 1832-1837.

6. Botsaris G., Nikolaou K., Liapi M., Pipis C.: Prevalence of Listeria spp. and Listeria monocytogenes in cattle farms in Cyprus using bulk tank milk samples. J. Food Safety 2016, 36, 482-488.

7. Carryn S., Van Bambeke F., Mingeot-Leclercq M. P., Tulkens P. M. Comparative intracellular (THP-1 macrophage) and extracellular activities of beta-lactams, azithromycin, gentamicin, and fluoroquinolones against Listeria monocytogenes at clinically relevant concentrations. Antimicrob. Agents Chemotherap. 2002, 46, 2095-2103.

8. Chye F. Y., Abdullah A., Ayob M. K.: Bacteriological quality and safety of raw milk in Malaysia. Food Microbiol. 2004, 21 (5), 535-541.

9. Dzierżanowska D.: Antybiotykoterapia Praktyczna. Alfa Medica Press 2018, 109-110, 288-289.

10. EFSA (European Food Safety Authority): The European Union One Health 2019 Zoonoses Report. EFSA Journal. 2021, doi: 10.2903/j.efsa.2021.6406.

11. EFSA (European Food Safety Authority): The European Union One Health 2018 Zoonoses Report. EFSA Journal. 2019, doi: 10.2903/j.efsa.2019.5926.

12. El Marnissi B., Bennani L., Cohen N., El Ouali Lalami A., Belkhou R.: Presence of Listeria monocytogenes in raw milk and traditional dairy products marketed in the north-central region of Morocco. Afr. J. Food Sci. 2013, 7 (5), 87-91.

13. Farber J. M., Peterkin P. I.: Listeria monocytogenes, a food-borne pathogen. Microbiol. Rev. 1991, 55 (3), 476-511.

14. Founou L. L., Founou R. C., Essack S. Y.: Antibiotic resistance in the food chain: a developing country perspective. Front. Microbiol. 2016, 7, 1881.

15. Freitas Kobayashi P. de, de Carvalho A. F., Fredrigo R. C., Costa A. M., Piatti R. M., Scarcelli Pinheiro E.: Detection of Brucella spp., Campylobacter spp. and Listeria monocytogenes in raw milk and cheese of uninspected production in the metropolitan area of São Paulo. Semina: Ciências Agrárias 2018, 38 (4), 1897-1904.

16. Golob M., Mijovič A., Krt B., Zdovc I.: Listeria monocytogenes in raw milk from farm bulk tank - How to find a source of contamination. Slov. Vet. Res. 2011, 48, 296-299.

17. Guillet Ch., Join-Lambert O., Le Monnier A., Leclercq A., Mechaï F., MamzerBruneel M. F., Bielecka M. K., Scortti M., Disson O., Berche P., VazquezBoland J., Lortholary O., Lecuit M.: Human Listeriosis Caused by Listeria ivanovii. Emerg. Infect. Dis. 2010, 16 (1), 136-138.

18. Hendriksen R. S., Mevius D. J., Schroeter A., Teale C., Meunier D., Butaye P., Franco A., Utinane A., Amado A., Moreno M., Greko C., Stärk K., Berghold C., Myllyniemi A. L., Wasyl D., Sunde M., Aarestrup F. M.: Prevalence of antimicrobial resistance among bacterial pathogens isolated from cattle in different European countries: 2002-2004. Acta Vet. Scand. 2008, 50, 28, 1-10. 
19. Hof $H$. : An update on the medical management of listeriosis. Expert Opin. Pharmacol. 2004, 5 (8), 1727-1735.

20. Jaakkonen A., Kivisto R., Aarnio M., Kalekivi J., Hakkinen M.: Persistent contamination of raw milk by Campylobacter jejuni ST-883. PLOS ONE 2020, 15 (4), 1-22.

21. Jamali H., Radmehr B., Thong K.-L.: Prevalence, characterization, and antimicrobial resistance of Listeria species and Listeria monocytogenes isolates from raw milk in farm bulk tanks. Food Control. 2013, 34, 121-125.

22. Janakiraman V.: Listeriosis in pregnancy: diagnosis, treatment and prevention. Rev. Obstet. Gynecol. 2008, 1 (4), 179-185.

23. Jemmi T., Stephan R.: Listeria monocytogenes food-borne pathogen and hygiene indicator. Rev. Sci. Tech. Off. Int. Epiz. 2006, 25, 571-580.

24.Julien M.-C., Dion P., Lafreniere C., Antoun H., Drouin P.: Sources of Clostridia in raw milk on farms. Appl. Environ. Microbiol. 2008, 74 (20), 6348-6357.

25. Keyvan E., Yurdakul O., Demirtas A., Yalcin H., Bilgen N.: Identification of methicillin-resistant Staphylococcus aureus in bulk tank milk. Food Sci. Technol. 2020, 40 (1), 150-156.

26. Konosonoka I. H., Jemeljanovs A., Osmane B., Ikauniece D., Gulbe G. Incidence of Listeria spp. in dairy cows feed and raw milk in Latvia. ISRN Vet. Sci. 2012, 1-5

27. KorsakD., BorekA., Daniluk S., Grabowska A., Pappelbaum K.: Antimicrobial susceptibilities of Listeria monocytogenes strains isolated from food and food processing environment in Poland. Int. J. Food Microbiol. 2012, 158 (3), 203-208

28. Korsak D., Szuplewska M.: Characterization on nonpathogenic Listeria species isolated from food and food processing environment. Int. J. Food Microbiol. 2016, 238, 274-280

29. Lemaire S., Van Bambeke F., Mingeot-Leclercq M. P., Tulkens P. M.: Activity of three $\beta$-lactams (ertapenem, meropenem and ampicillin) against intraphagocytic Listeria monocytogenes and Staphylococcus aureus. J. Antimicrob. Chemoth. 2005, 55, 897-904.

30.Lin J., Nishino K., Roberts M. C., Tolmasky M., Aminov R., Zhang L.: Mechanisms of antibiotic resistance. Front. Microbiol. 2015, 6, 1-3.

31.Luque-Sastre L., Arroyo C., Fox E. M., McMahon B. J., Bai L., Li F., Fanning S.: Antimicrobial resistance in Listeria species. Microbiol. Spectr. 2018, 6 (4), 1-23.

32. Mansouri-Najand L., Kianpour M., Sami M., Jajarmi M.: Prevalence of Listeria monocytogenes in raw milk in Kerman, Iran. Vet. Res. Forum. 2015, 6 (3), 223-226

33. Marco F., Almela M., Nolla-Salas J., Coll P., Gasser I., Ferrer M. D., de Simon $M$ : In vitro activities of 22 antimicrobial agents against Listeria monocytogenes strains isolated in Barcelona, Spain. The Collaborative Study Group of Listeriosis of Barcelona. Diagn. Micr. Infec. Dis. 2000, 38, 259-261.

34. Mehli L., Hoel S., Thomassen G. M. B., Nordeng-Jakobsen A., Karlsen H.: The prevalence, genetic diversity and antibiotic resistance of Staphylococcus aureus in milk, whey, and cheese from artisan farm dairies. Int. Dairy J. 2017, 65, 20-27.

35. Morvan A., Moubareck C., Leclercq A., Herve-Bazin M., Bremont S., Lecuit M., Courvalin P., Le Monnier A. Antimicrobial resistance of Listeria monocytogenes strains isolated from humans in France. Antimicrob. Agents Ch. 2010, 54 (6), 2728-2731

36. Murinda S. E., Nguyen L. T., Ivey S. J., Oliver S. P.: Prevalence and molecular characterization of Escherichia coli O157:H7 in bulk tank milk and fecal samples from cull cows: a 12-month survey of dairy farms in East Tennessee. J. Food Protect. 2002, 65 (5), 752-759.

37. Orsi R. H., Wiedmann M.: Characteristics and distribution of Listeria spp., including Listeria species newly described since 2009. Appl. Microbiol. Biotechnol. 2016, 100, 5273-5287.

38. Pantoja J. C. F., Rodrigues A. C. O., Hulland C., Reinemann D. J., Ruegg P. L.: Investigating contamination of bulk tank milk with Listeria monocytogenes on a dairy farm. Food Protect. Trend. 2012, 32 (9), 512-521.

39. PN-EN ISO 11290-1: 2017-07: Food chain microbiology - Horizontal method for the detection and enumeration of Listeria monocytogenes and other Listeria spp. - Part 1: Detection method.

40. Porcellato D., Aspholm M., Skeie S. B., Monshaugen M., Brendehaug J., Mellegard H.: Microbial diversity of consumption milk during processing and storage. Int. J. Food Microbiol. 2018, 266, 21-30.

41. Rahimi A., Ameri M., Momtaz H.: Prevalence and antimicrobial resistance of Listeria species isolated from milk and dairy products in Iran. Food Control. 2010, 21 (11), 1448-1452.

42. Rocourt J.: Risk factors for listeriosis. Food Control. 1996, 7, 195-202.

43. Rudolf M., Scherer S.: High incidence of Listeria monocytogenes in European red smear cheese. Int. J. Food Microbiol. 2001, 63, 91-98.

44. Skowron K., Hulisz K., Gryń G., Olszewska H., Wiktorczyk N., Paluszak Z. Comparison of selected disinfectants efficiency against Listeria monocytogenes biofilm formed on various surfaces. Int. Microbiol. 2018, 21, 23-33.
45. Skowron K., Wiktorczyk N., Grudlewska K., Kwiecińska-Piróga J., WałeckaZacharskab E., PaluszakZ., Gospodarek-Komkowska E.: Drug-susceptibility, biofilm-forming ability and biofilm survival on stainless steel of Listeria spp. strains isolated from cheese. Int. J. Food Microbiol. 2019, 296, 75-82.

46. Snapir Y. M., Vaisbein E., Nassar F.: Low virulence but potentially fatal outcome Listeria ivanovii. Eur. J. Intern. Med. 2006, 17 (4), 286-287.

47. Srinivasan V., Nam H. M., Nguyen L. T., Tamilselvam B., Murinda S. E., Oliver S. P.: Prevalence of antimicrobial resistance genes in Listeria monocytogenes isolated from dairy farms. Foodborne Pathog. Dis. 2005, 2 (3), 201-211.

48. Temple M. E., Nahata M. C.: Treatment of listeriosis. Ann. Pharmacother 2000, 34 (5), 656-661

49. Van Kessel J. S., Karns J. S., Gorski L., McCluskey B. J., Perdue M. L. Prevalence of Salmonellae, Listeria monocytogenes and fecal coliforms in bulk tank milk on US dairies. J. Dairy Sci. 2004, 87 (9), 2822-2830.

50. Vazquez-Boland J. A., Kuhn M., Berche P., Chakraborty T., DominguezBernal G., Goebel W., González-Zorn B., Wehland J., Kreft J.: Listeria pathogenesis and molecular virulence determinants. Clin. Microbiol. Rev. 2001, 14 (3), 584-640.

51. Vázquez-Salinas C., Rodas-Suárez O., Quiñones-Ramírez E. I.: Occurrence of Listeria species in raw milk in farms on the outskirts of Mexico city. Food Microbiol. 2001, 18, 177-181.

52. Waak E., Tham W., Danielsson-Tham M. L.: Prevalence and fingerprinting of Listeria monocytogenes strains isolated from raw whole milk in farm bulk tanks and in dairy plant receiving tanks. Appl. Environ. Microb. 2002, 68 (7), 3366-3370.

53. Walczycka M.: Metody inaktywacji i hamowania wzrostu Listeria monocytogenes $w$ przetworach mięsnych. Żywn. Nauka Technol. Jakość 2005, 43, 61-72.

54. Weller D., Andrus A., Wiedmann M., den Bakker H. C.: Listeria booriae sp. nov. and Listeria newyorkensis sp. nov., from food processing environments in the USA. Int. J. Syst. Evol. Microbiol. 2015, 65, 286-292.

55. WHO fact sheet. Antimicrobial resistance. 1998, 194.

56. Wise R.: Antimicrobial resistance is a major threat to public health (Editorial). Brit. Med. J. 1998, 317, 609-610.

57. Wiszniewska-Laszczych A., Zdrodowska B., Wysok B., Szteyn J., Liedtke K., Gomótka-Pawlicka M., Wojtacka J.: Ocena wystepowania plazmidowych genów zjadliwości spv oraz antybiotykooporność szczepów Salmonella izolowanych z mleka. Vet. Med. 2018, 74 (1), 59-64.

58. Wysok B., Wiszniewska-Łaszczych A., Uradziński J., Szteyn J.: Prevalence and antimicrobial resistance of Campylobacter in raw milk in the selected areas of Poland. Pol. J. Vet. Sci. 2011, 14 (3), 473-477.

Autor korespondencyjny: mgr Marta Maria Soltysiuk, ul. Oczapowskiego 14, 10-718 Olsztyn - Kortowo, Poland; e-mail: marta.soltysiuk@uwm.edu.pl 